\title{
Tenencia de la propiedad en la Costa Caribe de Nicaragua
}

\author{
Property Ownership in the Nicaraguan Caribbean Coast
}

Sandra Carolina Rojas Hooker ${ }^{1}$

\section{Resumen}

Este artículo se basó en el estudio "Tipos de tenencia de la propiedad en la Costa Caribe de Nicaragua" con énfasis en la identificación de las formas de propiedad reconocidas en la legislación nicaragüense, régimen especial que regula el uso y tenencia de la propiedad y las zonas de mayor demanda para la adquisición en la Costa Caribe de Nicaragua. El derecho a la propiedad es el derecho real por excelencia ya que comprende una serie de facultades que una persona o colectividad puede tener sobre ella. La Constitución Política de Nicaragua reconoce las diferentes formas de propiedad: pública, privada, asociativa, cooperativa, comunitaria, comunal, familiar y mixta y las formas de accesar a la misma a través de los diferentes sistemas de tenencia. La identificación plena de las diferentes categorías, los derechos que se puedan ejercer de acuerdo a la tenencia y adquisición de propiedades en la Costa Caribe constituye un requisito indispensable para brindar seguridad jurídica en la tenencia de la propiedad y la promoción de las inversiones en la Costa Caribe de Nicaragua.

Palabras clave: Tenencia de la propiedad, formas de propiedad, derechos colectivos.

\section{Abstract}

This article was based on the study "Types of property ownership in the Nicaraguan Caribbean Coast" with emphasis in the property forms identification known in the Nicaraguan Legislation, special regimen that regulates the use and ownership of properties and the zones with a great demand for the acquisition in the Caribbean Coast of Nicaragua. The right to the property is the real right for excellence because it comprehends a series of faculties that a person or community can have over it. The Political Constitution of Nicaragua recognizes the different forms of property: public, private, associative, collective, communitarian, communal, familiar and mixed, and the forms for accessing to them through the different ownership systems. The identification of the different categories, the rights that can be taken according to the ownership and acquisition of properties in the Caribbean Coast constitute an indispensable requirement to give legal security in the property ownership and the investment promotions in the Nicaraguan Caribbean Coast.

1 Máster en Estudios Indígenas. Directora del Instituto de Estudios y Promoción de la Autonomía de la Universidad de las Regiones Autónomas de la Costa Caribe Nicaragüense. Correo: sandra.rojas@uraccan.edu.ni; No. ORCID: https://orcid. org/0000-0002-7467-2366

Recibido: 05/02/2018 Aprobado: 30/04/2018

Rojas-Hooker, S. (2018). Tenencia de la propiedad en la Costa Caribe de Nicaragua. Ciencia E Interculturalidad, 22(1), 74-87. Dol: https://doi.org/10.5377/rci.v22i1.6558 
Keywords: Property Ownership; property forms, collective rights.

\section{Introducción}

La Costa Caribe de Nicaragua, con su diversidad étnica y cultural ocupa aproximadamente el 50\% del territorio nacional con una extensión territorial de $60,329.90 \mathrm{~km}^{2}$. Desde el año 2007 a noviembre 2016 se han titulado 23 territorios, 16 en la Costa Caribe Norte, 3 en la zona de régimen especial (Jinotega) y 4 en la Costa Caribe Sur que corresponden a 304 comunidades. El total del área demarcada y titulada es de $37,841.99 \mathrm{~km} 2$, equivalente a 31.6\% del territorio nacional. La población total de la Costa Caribe se estima en 816,718 habitantes, al de junio de 2013. Con base en los datos del Censo Nacional de 2005, de los cuales $77.7 \%$ de la población es mestiza; el 17.8\% son miskitus, residiendo principalmente en la Costa Caribe Norte; el 1.1\% es sumu-mayangna; el 3.0\% es creole, la mayoría de los cuales viven en la Costa Caribe Sur; el $0.2 \%$ de la población es rama e igualmente el $0.2 \%$ son garífunas. En su totalidad representa el 12.1\% de la población total de Nicaragua (INIDE, 2007b).

El reconocimiento de los derechos autonómicos fue incluido en la Constitución Política de Nicaragua de 1987 a través de los artículos 89, 180 y 181. Las Reformas Constitucionales de 2014 reconoce las distintas formas de propiedad: pública, privada, asociativa, cooperativa, comunitaria, comunal, familiar y mixta. En el caso particular de los pueblos originarios y afrodescendientes se les reconoce el derecho a mantener y desarrollar su identidad y cultura, tener sus propias formas de organización social y administrar sus asuntos locales, así como mantener las formas comunales de propiedad de sus tierras y el goce, uso y disfrute sobre las mismas de conformidad con la ley.

\section{Revisión de la literatura}

La tierra constituye un elemento fundamental para el ejercicio de los derechos de la gran mayoría de seres humanos. Los regímenes de tenencia están definidos socialmente por normas de acceso y de uso de los recursos, las cuales definen los derechos y deberes de la gente con respecto a estos, las cuales pueden estar escritas en las leyes, o pueden formar parte del derecho consuetudinario no escrito.

Según la FAO (2003):

Las reglas relativas a la tenencia de la tierra determinan como distribuyen en las sociedades los derechos de propiedad. Definen como se otorga el acceso a los derechos a utilizar, controlar y transferir la tierra, así como las pertinentes responsabilidades y limitaciones. En otras palabras, los sistemas de tenencia de la tierra determinan quién puede utilizar qué recursos, durante cuánto tiempo y en qué circunstancias. 
Para los pueblos indígenas, la tierra tiene un profundo valor cultural, no es visto únicamente como un factor productivo, es considerada como la fuente de todo poder y sabiduría, convirtiéndose en un elemento constitutivo de su condición como pueblo en virtud de que estos mantienen una especial relación con la tierra y el territorio.

El Convenio 169 de la OIT sobre Pueblos indígenas y Tribales de 1989 en su artículo 13 establece que al aplicar las disposiciones de este Convenio los gobiernos deberán respetar la importancia especial que para las culturas y valores espirituales de los pueblos interesados reviste su relación con las tierras o territorios, o con ambos, según los casos, que ocupan o utilizan de alguna manera. Agrega que, la utilización del término tierras incluye el concepto de territorios, que cubre la totalidad del hábitat de las regiones de que los pueblos interesados ocupan o utilizan de alguna otra manera, El territorio constituye un referente central para comprender las dinámicas jurídicas, políticas y sociales que han marcado la relación del Estado con los pueblos indígenas y afrodescendientes y de estas entre sí.

\section{Materiales y métodos}

El estudio es fundamentalmente una metodología cualitativa y con el soporte de la información cuantitativa disponible. Las principales técnicas de investigación utilizadas fueron la revisión documental, las entrevistas semi-estructuradas y los grupos focales. La revisión documental se efectuó principalmente en Bilwi, Siuna, Bluefields y Managua. Los grupos focales fueron ejecutados en las respectivas cabeceras municipales de Puerto Cabezas, Siuna, Bluefields y Nueva Guinea, con la participación de 45 personas. Por su parte, en total se realizaron cuatro entrevistas grupales a 23 miembros de las diferentes Juntas Directivas de los Gobiernos Territoriales y 20 entrevistas directas a funcionarios públicos, abogados y notarios y otras personalidades.

\section{Resultados y discusión}

La Constitución Política de Nicaragua reformada en el 2014 reconoce ocho formas de propiedad que son: pública, privada, asociativa, cooperativa, comunitaria, comunal, familiar y mixta.

\section{Propiedad Pública}

Se encuentra bajo la Administración Pública, según disponga la misma Constitución o las leyes especiales u ordinarias. La propiedad pública recae sobre bienes cuya titularidad corresponde al Estado o a otras entidades públicas y están adscritos a un uso o servicio público; las características que la distinguen de la propiedad privada, es que 
ella está fuera del comercio, es decir, son inalienables, imprescriptibles, inembargables y los particulares no pueden deducir acciones reivindicatorias.

Se desconoce el área total de la propiedad pública perteneciente al Estado, ya que una buena parte de ella no está carrilada, ni catastrada y son ocupadas por particulares provenientes de otras regiones del país o nativos del lugar quienes realizan cesiones de derecho sobre ellas a título gratuito u oneroso, aún cuando gozan de una tenencia o posesión precaria sobre las mismas. Estos derechos sobre la tierra no son inscribibles puesto que no se han sometido a ningún proceso de legalización.

\section{Propiedad privada}

La Constitución Política de Nicaragua, como principio general garantiza a todos los ciudadanos nacionales y extranjeros el derecho de propiedad privada de todo tipo de bienes: muebles e inmuebles; estando únicamente sujetos por causa de utilidad pública o de interés social a limitaciones y obligaciones en su ejercicio reguladas por las leyes especiales u ordinarias.

La confiscación de bienes está prohibida y se establece la expropiación de los mismos por razones de utilidad pública teniendo derecho el propietario de los bienes afectados a una justa indemnización de acuerdo con la ley de la materia; según la finalidad o nuevo uso que se le dará al bien. Las propiedades privadas son las adquiridas por particulares sean estas personas naturales o jurídicas en legítimo provecho de sus intereses específicos y personales. Derechos que son de carácter exclusivo y transferible. El artículo 613 del Código Civil establece que son particulares, las cosas cuya propiedad pertenece a personas naturales o jurídicas, y de que nadie puede beneficiarse, sino aquellas personas u otras por las mismas autoridades.

Corresponde al dominio de los particulares el uso y goce de los mismos. Por ende, se garantiza el derecho de propiedad privada de los bienes muebles e inmuebles, los instrumentos y medios de producción. En virtud de la función social de la propiedad, este derecho está sujeto, por causa de utilidad pública o de interés social, a las limitaciones y obligaciones que en cuanto a su ejercicio le impongan las leyes. Los bienes inmuebles pueden ser objeto de expropiación de acuerdo a la ley, previo pago en efectivo de justa indemnización (Constitución Política de Nicaragua, 2014, Art. 44).

Se desconoce la extensión total de propiedades privadas en la Costa Caribe nicaragüense, ya que muchas de las personas que alegan tener derechos sobre dichas áreas son precaristas o tienen documentos con algún vicio de fondo o de forma y en algunos casos se encuentran asentados en propiedad pública (incluyendo áreas protegidas) o territorios comunales. 


\section{Propiedades asociativas}

Se produce cuando la propiedad de una cosa o la titularidad de un derecho corresponden en conjunto y proindiviso a varias personas ${ }^{2}$. Son tierras adquiridas para el uso y aprovechamiento por las diferentes formas de articulación organizativa de interés social.

Mediante la Ley No. 830, el Estado de Nicaragua reconoce la plena capacidad jurídica de las personas excombatientes y colaboradores como sujetas de derecho y obligaciones en igualdad de condiciones, entre estas la de gravar sus bienes salvo en los casos cuando el Estado le hubiere adjudicado propiedad alguna no podrá ser objeto de venta y en caso fortuito el Estado deberá ser el único adquirente quién pagará el valor de las mejoras realizadas más el valor catastral. La cobertura de los programas se orienta a diez áreas temáticas, en las cuales destaca la legalización y tenencia de la propiedad de conformidad con la ley de la materia ${ }^{3}$.

Usualmente ostentan títulos colectivos en grupos de 10 personas en áreas definidas de 500 manzanas (352.5 hectáreas). Al ser copropietarios del fundo pueden enajenar a título individual o colectivamente y son atractivas la inversión extranjera en estos terrenos por el posicionamiento geográfico que tienen y los recursos naturales que disponen. Los títulos y enajenaciones son inscribibles.

\section{Propiedad cooperativa}

Es la propiedad conjunta perteneciente a una asociación autónoma de personas que se unen voluntariamente para hacer frente a sus necesidades y aspiraciones económicas, sociales y culturales comunes. En la propiedad de grupo su importancia reside en que todos los cooperativistas administran la propiedad para su beneficio individual y colectivo, con rendimientos razonables. Es decir, unen recursos para ayudarse mutuamente a mejorar sus condiciones de vida.

La propiedad cooperativa es una forma no muy utilizada en la Costa Caribe puesto que es ajena a la cultura del lugar. Existe en pequeña escala principalmente en el sector minero de la Región Autónoma de la Costa Caribe Norte entre campesinos mestizos pertenecientes a las extintas cooperativas agrarias sandinistas creadas en la década de los ochenta del siglo XX. Su régimen constitutivo y organizativo se rige por la Ley General de Cooperativas y su Reglamento y es una forma atractiva para la inversión cuando de interés social se trata al gozar de una serie de prerrogativas en materia fiscal y tributaria. El IV CENAGRO registra siete cooperativas en las Regiones Autónomas; dos en el Sur y cinco en el Norte. Estos últimos están localizados en el Triángulo Minero.

2 Ver art. 1692 a 1714 C, de la Comunidad de Bienes.

3 Consultar artículos 27 apartado 1 y 52 de la ley 830. 


\section{Propiedad comunal}

Es la propiedad constituida por las tierras, agua, bosques y otros recursos naturales contenidos en ellas, que han pertenecido tradicionalmente a la comunidad, conocimientos tradicionales, propiedad intelectual y cultural, recursos de biodiversidad y otros bienes, derechos y acciones que pertenezcan a una o más comunidades indígenas o étnicas (Ley 445, Art.3; Reglamento de la Ley 28, Art. 3). La propiedad comunal goza de una protección especial estatal. Son imprescriptibles, inalienables e inembargables, por lo tanto, sólo pueden ser objeto de uso, goce y disfrute por medio de contratos de arrendamientos; cesiones de derecho de arrendatarios con la anuencia de la comunidad y de manera particular para efecto de inversiones nacionales, mixtas o extranjeras: Convenios, concesiones estatales o memorándum de entendimiento.

En el caso de los pueblos indígenas y afrodescendientes en su calidad de titulares de las tierras comunales disponen gratuita e indefinidamente de ella. Este derecho se transmite a sus familiares sin que medie documento, atendiendo a la tradición oral. Incluso, se permite la cesión de derecho de tenencia a favor de un tercero no indígena en casos especiales como podría ser aquellos que están casados o en unión de hecho estable con alguien de la comunidad y que se quedan viviendo en la comunidad.

Las distintas formas de tenencia de la tierra en territorios indígenas y afrodescendientes son:

1. Tierras en manos de particulares no indígenas adquiridas antes de 1987.

2. Tierras en manos de particulares no indígenas con documentos válidos que se asentaron en áreas protegidas antes de 1999 y antes de iniciar el proceso de titulación de los territorios indígenas.

3. Tierras en manos de particulares no indígenas en territorios indígenas sin ningún derecho sobre ella.

4. Lotes de terrenos en manos de particulares no indígenas que han sido entregados por autoridades comunitarias.

Las principales complejidades que se presentan en la propiedad comunal son las siguientes:

1. La creciente población no indígena en territorios indígenas, tensiona en muchas ocasiones la relación entre ellos o con otros que llegan a querer ocupar los terrenos que ellos tienen de forma ilegal y todos ellos con los indígenas. El punto más alto en este tensionamiento gira alrededor de la tenencia de la tierra y sus recursos y en muchas ocasiones ha desembocado en quemas de viviendas, destrucción de siembros, lesiones y muertes. 
2. La politización y partidización en la elección de las autoridades comunitarias potencia la inseguridad jurídica en la contratación, porque las nuevas autoridades electas muchas veces no reconocen ni respetan los acuerdos, convenios y contratos realizados con las anteriores autoridades. También son frecuentes las divergencias en el reparto de las utilidades.

3. El desfase y la falta de conclusión de la etapa de saneamiento impide la emisión de los títulos de propiedad a favor de las comunidades indígenas y consecuentemente dificulta las negociaciones para la inversión.

4. De manera general, todas las formas de tenencia de la tierra en la Costa Caribe nicaragüense están limitadas en su ejercicio ya sea por utilidad pública e interés social o por leyes especiales que regulan las áreas protegidas, terrenos fronterizos y costeros. También están reguladas según el giro del negocio o uso que se le pretenda dar. Nicaragua tiene una legislación suficientemente amplia que garantiza la seguridad de la inversión nacional y extranjera; para el caso de la Costa Caribe nicaragüense solamente es observar y atender la cultura del lugar y las disposiciones legales vigentes.

\section{Comunitaria}

Son aquellos de uso colectivo, cuyos propietarios pueden ser las alcaldías municipales, los pueblos indígenas, afrodescendientes, mestizos y otras comunidades étnicas.

\section{Familiar}

La familia es el núcleo fundamental de la sociedad y goza de la protección estatal (art. 170 Cn.) En relación a la propiedad familiar el Decreto No. 415, ley orgánica del patrimonio familiar aprobado el 12 de marzo de 1959 nos da una definición de lo que se entiende por patrimonio familiar, a saber:

Artículo 1. Para los efectos del artículo 75 de la Constitución Política, se entiende por Patrimonio Familiar los bienes inmuebles que se separan del patrimonio particular de una persona y se vinculan directamente a una familia de escasos recursos económicos, con el fin de asegurarle la mejor satisfacción de sus necesidades. Habrá dos clases de patrimonio familiar: urbano y rural, según los bienes que lo constituyen que se encuentren en zona urbana o rural.

\section{Mixta}

Sobre propiedad mixta la única referencia existente es la contenida el III CENAGRO, que hace referencia a la tenencia mixta referida a las explotaciones agropecuarias con tierras de una o más formas de tenencia, o combinaciones de todas las anteriores. 


\section{Régimen especial que regula el uso y tenencia de la propiedad}

La Constitución Política de Nicaragua establece la obligación del Estado de respetar las diversas formas de propiedad dentro de un modelo de economía mixta supeditadas únicamente a los intereses superiores de la nación y cumplen una función social. No se perturbará el dominio y posición legal de cualquiera de estas formas de propiedad. Excepto en los casos que determine la ley (Art. $103 \mathrm{Cn}$ ).

De tal manera, el respeto al derecho de propiedad privada y el uso goce y disfrute de los bienes públicos no es absoluto. En dependencia de intereses superiores de la nación como puede ser el uso racional de sus recursos naturales o de defensa y seguridad; o de una función social como el paso de una calle o carretera. Esta puede estar sujeta a regulaciones especiales que limitan el ejercicio de este derecho o lo suprimen como el caso de expropiación.

Las principales regulaciones especiales de la tenencia de la tierra en las Regiones Autónomas son las siguientes:

\section{Áreas protegidas}

En Nicaragua existen nueve categorías de áreas protegidas: Reserva Biológica, Parque Nacional, Monumento Nacional, Monumento Histórico, Reserva de Vida Silvestre, Reserva Natural, Paisaje Terrestre o Marino Protegido y Reserva de Biósfera cuyo uso está condicionado por leyes especiales.

El artículo 23 de la Ley General del Medio Ambiente y los Recursos Naturales (ley No. 217) estipula que todas las tierras de propiedad privada situadas en áreas protegidas están sujetas a las condiciones de manejo establecidas en las leyes de la materia. Los derechos adquiridos de los propietarios que no acepten las nuevas condiciones que se establezcan estarán sujetos a declaración de utilidad pública, previo pago en efectivo de justa indemnización.

El MARENA podrá autorizar la construcción de estaciones de servicios e investigación, así como dar en administración las áreas protegidas propiedad del Estado a terceros, pudiendo solicitar el co-manejo de las mismas los organismos e instituciones nicaragüenses sin fines de lucro, municipalidades, universidades, instituciones científicas, cooperativas, comunidades indígenas y comunitaria bajo las condiciones y normas que sobre la materia se establezca en el respectivo plan de manejo. Esta cesión es de diez años a partir de la fecha del convenio que podrá renovarse por períodos iguales de acuerdo a la evolución y cumplimiento de las condiciones de manejo del área.

La presión de los colonos procedentes de otras regiones del país con la venia de algunos lugareños y autoridades locales ha provocado la invasión de tierras en las 
Regiones Autónomas, aún en las áreas protegidas. Estas personas además de exponerse a sanciones penales se exponen a perder sus inversiones al verse imposibilitados de legalizar el acceso a esas tierras que, aún en el supuesto caso que hayan inscrito algún derecho sobre ellas, siempre podrán ser objeto de limpieza o saneamiento registral quedando las cosas en su estado origen; es decir, en la forma y modo que estableció la ley.

\section{Áreas costeras}

Ley No. 69o, ley para el desarrollo de las zonas costeras en su artículo 33 establece la declaratoria de utilidad pública para servidumbre de paso. De conformidad con el artículo 44 esta disposición que no es aplicable a las Regiones Autónomas ya que, el artículo 33 de la Ley No. 445 estipula que las comunidades indígenas y étnicas del litoral, islas y cayos del Atlántico, tienen derecho exclusivo para el aprovechamiento de los recursos marítimos para pesca comunitaria y artesanal, dentro de las tres millas adyacentes al litoral y veinticinco millas de los cayos e islas adyacentes.

\section{Áreas fronterizas}

La ley No.749, ley de régimen jurídico de fronteras señala que, en el territorio fronterizo, ninguna persona natural o jurídica puede adquirir por prescripción cualquier derecho real sobre los bienes del Estado, y de los Municipios que estuvieren destinados a un servicio público. Solamente podrán darse en concesión los bienes de dominio público, por causas de interés social o público o autorizaciones de arrendamiento otorgadas por el Poder Ejecutivo por medio de Acuerdo Presidencial, de conformidad con esta ley o leyes especiales.

Estos bienes inmuebles que no están sujetos a expropiación por causa de utilidad pública. Tampoco pueden ser objeto de hipoteca, ni reportar en provecho de particulares o personas jurídicas, ningún derecho de usufructo, de uso o de habitación, directa o subsidiariamente, o como garantía de una responsabilidad pecuniaria, fuera de las causas consignadas en esta ley. A la vez prohíbe los asentamientos y la titulación a particulares dentro de las áreas protegidas; sin perjuicio de los derechos que tienen los pueblos indígenas y comunidades étnicas de conformidad a la ley de la materia. Establece como Zona de Seguridad Fronteriza aquella área inalienable del Estado de Nicaragua, comprendida desde el límite fronterizo convencional y los cinco kilómetros hacia el interior del territorio nacional, sometida a régimen especial.

El 13 de febrero del 2013 mediante circular de la Corte Suprema de Justicia a los Registradores Públicos de la Propiedad Inmueble y Mercantil se les recuerda que en virtud del artículo 38 de la Ley No. 749, los Registradores Públicos se abstendrán de inscribir las escrituras en las cuales se pretenda transferir cualquier tipo de derecho sobre los bienes inmuebles que se encontraren en el territorio fronterizo en 
contravención a lo dispuesto en esta ley. El traspaso de cualquier derecho contrario a esta disposición es nulo.

De manera general, todas las formas de tenencia de la tierra en la Costa Caribe nicaragüense están limitadas en su ejercicio ya sea por utilidad pública e interés social o por leyes especiales que regulan las áreas protegidas, terrenos fronterizos y costeros. También están reguladas según el giro del negocio o uso que se le pretenda dar. Nicaragua tiene una legislación suficientemente amplia que garantiza la seguridad de la inversión nacional y extranjera; para el caso de la Costa Caribe nicaragüense solamente es observar y atender la cultura del lugar y las disposiciones legales vigentes.

\section{Mecanismos de adquisición de la propiedad}

\section{Títulos otorgados por el Estado de Nicaragua a colectivos, empresas y particulares}

Los únicos títulos de propiedad debidamente registrados después de la Reincorporación de la Moskitia y el Tratado Harrison-Altamirano son:

5. Los otorgados a los pueblos indígenas y comunidades cuyos derroteros son imprecisos por falta de mediciones.

6. Los terrenos dados en concesiones para la explotación a favor de compañías extranjeras.

7. Los terrenos dados a particulares o reconocidos por el Estado a favor de particulares mediante títulos supletorios que generaron primer asiento.

Las formas de transmisión de los derechos sobre la tierra en la Costa Caribe nicaragüense dependen del origen de la misma, el giro de negocio que se pretenda y los sujetos que pretenden el negocio.

\section{Según el origen de la misma:}

La transmisión de la propiedad privada entre particulares opera bajo las formas establecidas en el código civil en tanto, la transmisión de la propiedad en áreas comunales está limitada a uso, goce y disfrute; es decir, a la mera tenencia sea por medio de un convenio dado por las comunidades o mediante contrato de arriendo, uso o usufructo.

En ambas situaciones, el ejercicio de los derechos está limitado por leyes especiales algunas de las que han sido mencionados la que establece las áreas protegidas, terrenos fronterizos o costeros. 
Según el giro del negocio que se pretenda:

También está regulado su ejercicio por el giro del negocio o uso que se le pretenda dar como por ejemplo la explotación minera o maderera, debe cumplir previamente una serie de requisitos especiales establecidos en las leyes de la materia.

Según la condición del sujeto que la pretenda:

Los indígenas y afrodescendientes dueños de la tierra pueden disponer de ella gratuita e indefinidamente; según su costumbre pueden transmitir ese derecho a sus familiares sin que medie ningún documento inclusive, atendiendo a la tradición oral.

En algunos casos, se le permite transmitir ese derecho a un tercero no indígena, pero en este caso no transfiere los privilegios que tiene el cedente como nativo de la comunidad. El pagar o no un canon de arriendo a la comunidad depende mucho del negocio que pretenda; así por ejemplo, si se casa con una nativa puede obtener gratuitamente un área de terreno en el que construirá su casa y tendrá sus siembras.

En el caso de los extranjeros, además de cumplir con requisitos generales deben de cumplir con requisitos especiales contenidos en la ley de inversiones extranjeras, ley de migración, leyes tributarias, leyes mercantiles, entre otras.

Transmisión de la propiedad entre particulares

El Código Civil, establece los mecanismos de adquisición de tenencia de la tierra entre particulares cuyas propiedades no se encuentren en territorios Indígenas, ni en áreas públicas sujetas a régimen especial, destacándose la compraventa, la cesión de derechos posesorios con venta de mejoras y la donación entre vivos y la herencia o legado por razón de muerte del propietario.

Zonas de mayor demanda para la adquisición de propiedad de acuerdo a su categoría

Existen factores que influyen o son determinantes en la actividad y desarrollo económico de una Región, entre ellos: la infraestructura pública, infraestructura vial, seguridad ciudadana, presencia de instituciones estatales que crea ambiente de estabilidad social y jurídica que se traduce en un aumento de inversión y generación de empleos directos e indirectos.

En las dos Regiones Autónomas existen Registros de la Propiedad de Bienes Inmuebles (Bilwi y Bluefields) sin embargo, el mayor problema que se enfrenta es la lejanía para el acceso a los mismos, encareciendo los costos a los propietarios de tierras para la inscripción de sus derechos por lo que optan en su mayoría a no inscribirlo. Sumado a esto, la falta de una orientación adecuada desde el punto de vista legal los 
hace incurrir en violaciones a la ley o equivocan los trámites generándose documentos que no son inscribibles.

La cantidad de propiedades registradas es inferior y no muy significativa del verdadero espectro de la tenencia de la tierra en la Costa Caribe, puesto que la titularidad sobre las mismas no está inscrita. Por lo que es sumamente difícil contar con una base de datos actualizada que nos permita tener luces sobre las zonas de mayor demanda para la adquisición de propiedad basados en el Registro Público.

No obstante, el IV Censo Nacional Agropecuario (IV CENAGRO) da pautas de las zonas de mayor demanda, tomando como referencia la Sección IV de la boleta donde se expone la situación del aprovechamiento y tenencia de la tierra en la cual se encuentra detallada los tipos de documentos por tenencia de la tierra: Cesión de derechos posesorios, promesa de venta, titulo de reforma agraria, titulo agrario, título real, titulo Harrison- Altamirano, documentos entregados por la Alcaldía, Declaratoria de Herederos y título supletorio.

Los resultados de este censo efectuado en el 2011 reflejan que el mayor porcentaje de las promesas de ventas se localizan en los municipios de Waslala con un $19 \%$, Siuna con un $17 \%$ y Mulukukú con $13 \%$ en la RACCN y en la RACCS, en la Cruz del Río Grande con 14\%, Paiwas con un 11\% y El Rama con 6\% respectivamente. Todos estos municipios tienen una mayoría poblacional mestiza y representan un mayor desarrollo de la ganadería extensiva.

La siguiente gráfica muestra estas tendencias a nivel municipal:

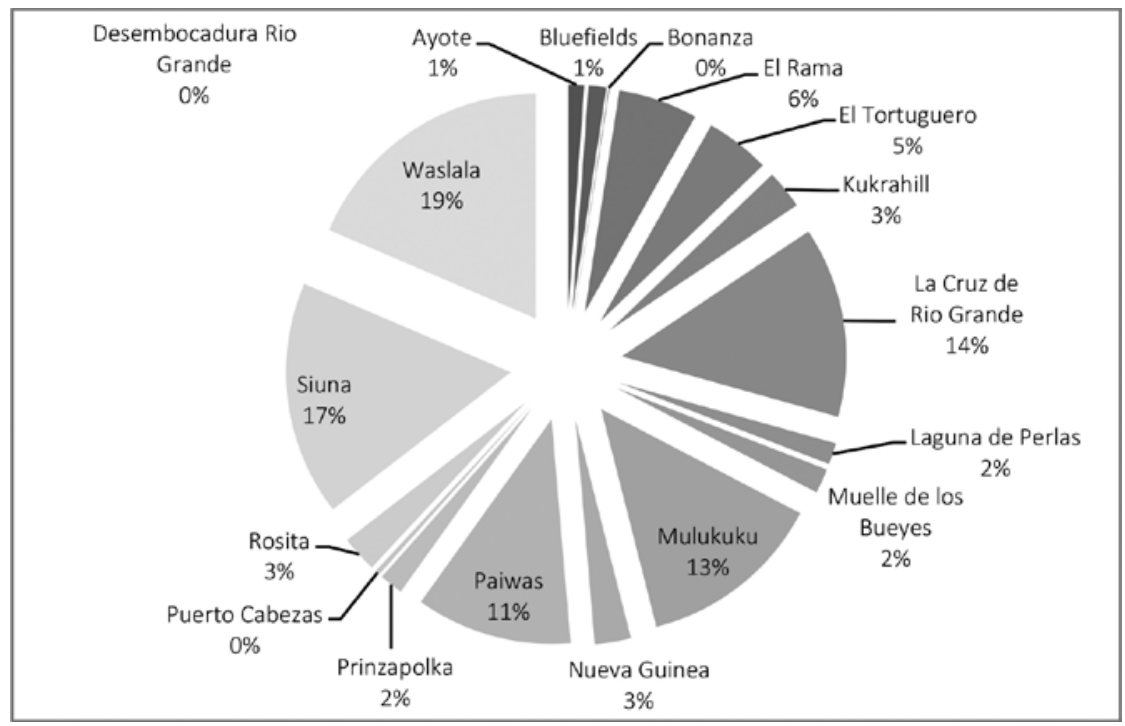

Fuente: IV CENAGRO, INIDE - MAGFOR, 2012 


\section{Conclusiones}

Si bien, la Constitución Política de Nicaragua reconoce, protege y promueve las distintas formas de propiedad, en la práctica se hace necesario un uso eficiente de los recursos asignados para el proceso de legalización de la tierra por parte de las instancias gubernamentales con presencia en la Costa Caribe de Nicaragua para lo cual es necesario tener en cuenta el régimen especial de propiedad existentes en la Costa Caribe y mantener una información actualizada sobre las zonas de mayor demanda que puedan incentivar la inversión en la Costa Caribe de Nicaragua.

Al no existir un inventario y registro actualizado de la propiedad en la Costa Caribe de Nicaragua dificulta los negocios entre particulares, y aumenta los riesgos en la inversión puesto que no se puede tener certeza de la legítima titularidad del que afirma tenerla. Esta situación trae como consecuencia, litigios por documentos falsos o ineficaces; emisión de títulos nulos por autoridades públicas no legitimadas para hacerlo; superposición (traslape) de supuestos derechos sobre un mismo fundo; conflictos por linderos; invasión de colonos y precaristas en propiedades privadas; disputas familiares por razones de herencia, entre otros.

\section{Lista de referencias}

Asamblea Nacional. (2014). Constitución Política de Nicaragua. Managua: La Gaceta Diario Oficial.

Asamblea Nacional. (1987). Ley $\mathrm{N}^{\circ}$ 28. Estatuto de Autonomía de las Regiones Autónomas de la Costa Atlántica de Nicaragua. Managua, La Gaceta Diario Oficial.

Asamblea Nacional (2012). Ley No 793 . Ley Creadora de la Unidad de Análisis Financiera. Managua: La Gaceta Diario Oficial.

Asamblea Nacional. (1904). Ley de Código Civil de la República de Nicaragua Managua: La Gaceta Diario Oficial.

Asamblea Nacional. (1990). Ley No 84. Ley de Cooperativas Agropecuarias y agroindustriales. Managua: La Gaceta Diario Oficial.

Asamblea Nacional. (2013). Ley $\mathrm{N}^{\circ}$ 830. Ley Especial para atención a excombatientes por la paz, unidad, y reconciliación nacional. Managua: La Gaceta Diario Oficial.

Asamblea Nacional. (1996). Ley No 217. Ley General del Medio Ambiente y los Recursos Naturales. Managua: La Gaceta Diario Oficial. 
Asamblea Nacional. (1997). Ley $\mathrm{N}^{\circ}$ 278. Ley sobre Propiedad Reformada Urbana y Agraria. Managua: La Gaceta Diario Oficial.

Asamblea Nacional. (1959). Ley Orgánica del Patrimonio Familiar, Decreto № 415, Managua: La Gaceta Diario Oficial.

Asamblea Nacional. (2009). Ley $\mathrm{N}^{\circ}$ 69o. Ley para el Desarrollo de Zonas Costeras, Ley № 69o. Managua: La Gaceta Diario Oficial.

Asamblea Nacional. (2014). Ley No 854. Ley de Reforma Parcial a la Constitución Política de Nicaragua. Managua: La Gaceta Diario Oficial.

Asamblea Nacional. (2010). Ley $\mathrm{N}^{\circ}$ 749. Ley de Régimen Jurídico de Fronteras, Ley №749, Managua: La Gaceta Diario Oficial.

Asamblea Nacional. (2003). Ley $\mathrm{N}^{\circ}$ 445. Ley de Régimen Propiedad Comunal de los Pueblos Indígenas y Comunidades Étnicas de las Regiones Autónomas de la Costa Atlántica de Nicaragua y los ríos Bocay, Coco e Indio Maíz, Ley № 445, Managua: La Gaceta Diario Oficial.

Instituto Nacional de Información de Desarrollo. (2007). Censo 2005. VIII Censo de Población y IV de Vivienda. Managua: INIDE.

Instituto Nacional de Estadísticas y Censos. (2002). III Censo Nacional Agropecuario. Resultados finales. Región Autónoma del Atlántico Norte. Volumen 17. Managua: INEC.

Instituto Nacional de Información de Desarrollo. (2012). Informe Final-IV Censo Nacional Agropecuario. Managua: INIDE

Organización de las Naciones Unidas para la Agricultura y Alimentación. (2003). Estudios sobre tenencia de tierra 3, Tenencia de la tierra y desarrollo Rural, Roma: FAO.

OIT. (1989). Convenio sobre pueblos indígenas y tribales en países independientes. Oficina Regional para América Latina y el Caribe: OIT. Recuperado el o6 de agosto 2018 en: http://www.ilo.org/wcmsp5/groups/public/---americas/---ro-lima/documents/publication/wcms_345065.pdf

ONU. (2007). Declaración de las Naciones Unidas sobre los derechos de los pueblos indígenas, Resolución 61/295. Recuperado el o6 de agosto de 2018 en: http://www. un.org/esa/socdev/unpfii/documents/DRIPS_es.pdf 